\title{
A method for the long-term exposure of rabbits to environmental pollutant gases
}

\author{
G.J. Douglas*, J.F. Price**, C.P. Page*
}

A method for the long-term exposure of rabbits to environmental pollutant gases. G.J. Douglas, J.F. Price, C.P. Page. CERS Journals Ltd 1994.

ABSTRACT: The aims of the present study were twofold. Firstly, we wanted to develop a system for the exposure of rabbits to pollutant gases that would monitor gas concentrations accurately, allow flexibility, be simple to operate, and could be constructed at relatively modest cost. Additionally, we wanted to determine whether the procedures necessary for the daily exposure of young rabbits had any detrimental effect on their development.

Using the environmental exposure system that we developed, littermate New Zealand White rabbits, neonatally immunized to either Alternaria tenuis or house dust mite antigen were exposed $2 \mathrm{~h}$ daily, from within $24 \mathrm{~h}$ of birth until 3 months of age, to either 4 ppm nitrogen dioxide $\left(\mathrm{NO}_{2}\right)$, or $5 \mathrm{ppm}$ sulphur dioxide $\left(\mathrm{SO}_{2}\right)$ or ambient air.

The environmental exposure system consists of four sections; a stainless steel exposure chamber; an airflow monitoring and control system and gas delivery system; a gas detector and monitoring system; and an exhaust fan. Equilibration and wash-out times of gas were short and the gas mixing within the chamber atmosphere was uniform. Levels of gases were reliably maintained throughout the period of exposure within predetermined limits. The weights of the immunized, gas-exposed animals did not differ significantly from those of the immunized, airexposed animals at any time throughout the 3 month period of exposure. At 3 months of age, the basal values for lung resistance and dynamic compliance did not differ between gas- and air-exposed rabbits. These values did not differ significantly from those obtained from naive animals of the same age.

Our results suggest that we have developed a sensitive, reliable and simple environmental exposure and monitoring system. It is anticipated that the methodology described will allow the careful investigation of the effects of long-term exposure to pollutant gases from birth on the development of airways hyperresponsiveness. Eur Respir J., 1994, 7, 1516-1526.

Interest in the influence of air pollution in the pathogenesis of asthma is growing, since the increasing prevalence of bronchial asthma in many countries [1-3] has no apparent primary cause [4]. In addition to any direct effects that environmental pollutants, such as nitrogen dioxide $\left(\mathrm{NO}_{2}\right)$ and sulphur dioxide $\left(\mathrm{SO}_{2}\right)$, may have on the airways, these gases have been implicated as adjuvant factors in the development of atopy and asthma [5-9]. Nevertheless, the precise contribution of such gases to the development of atopy or bronchial hyperresponsiveness is not yet known

Although results from animal models cannot be directly extrapolated to man, they provide a convenient method to investigate the effects of pollutant gases on sensitization and bronchial hyperresponsiveness, but such investigations necessitate the use of controlled atmosphere chambers. Such chambers are generally found only in specialized inhalation toxicology laboratories, and very often incorporate expensive sophisticated control systems for the maintenance of the internal environment [10]. If more than one gas are studied together, very expensive gas analysers are required. Descriptions of exposure
*Dept of Pharmacology, King's College, University of London, London, UK. **Dept of Thoracic Medicine, King's College Hospital, London, UK.

Correspondence: G.J. Douglas

Dept of Pharmacology

King's College

Manresa Road

London, SW3 6LX

UK

Keywords: Atmosphere exposure chambers controlled environment

environmental pollutants

nitrogen dioxide

rabbits

sulphur dioxide

Received: December 141993

Accepted after revision May 21994 chambers for use in animal studies are uncommon in the literature. The methodology outlined in papers dealing with exposure of animals tends to pay little attention to the equipment and techniques employed. Thus, the newcomer to this and related fields of research has scant information on which to base choice or design of equipment

HinNERs et al. [11] outlined a number of important considerations that must be taken into account in the design and construction of exposure chambers. Of primary importance is the maintenance of the desired conditions between predetermined limits within the chamber. There are a number of inexpensive sampling and assay techniques available for different gases that rely on a chemical reaction. However, these suffer from being either timeconsuming, both in chamber gas sample collection and performance, thus causing a delay in obtaining a reading, or from providing an average measurement of the concentration at single time-points only.

Over 20 yrs ago, neonatal immunization of rabbits with antigen and the adjuvant $\mathrm{Al}(\mathrm{OH})_{3}$ was reported to result in the preferential production of antigen specific immunoglobulin E (IgE) antibodies [12]. Using the same 
immunization protocol, SHAmPain et al. [13] and others $[14,15]$ have described how animals sensitized to either Alternaria tenuis or ragweed allergen undergo early and late airway responses to acute antigen challenge. These responses are attenuated by clinically useful anti-asthma drugs [16], and the animals develop 2-6 fold increases in acute airway responsiveness, which resolves in one week [14, 15, 17, 18]. Repeated measurements of lung function are readily made in the rabbit, and each animal may be used as its own control [18, 19]. Taking this all together, led us to use the rabbit as the species of choice in our experiments investigating the effects of exposure to pollutant gases from birth.

In the present study, we describe the design of a chamber and method for the exposure of rabbits to the pollutant gases $\mathrm{SO}_{2}$ and $\mathrm{NO}_{2}$. Neonatal immunization of rabbits to either Alternaria tenuis or an antigen from the house dust mite Dermatophagoides pteronyssinus has been used as part of an ongoing study investigating the mechanisms leading to the development of airway hyperresponsiveness. We have determined the effect of immunization and the procedures involved in the daily exposure of young rabbits to pollutant gases or ambient air upon the growth of these animals and on their pulmonary function.

\section{Methods}

\section{Animals}

New Zealand White rabbits of either sex (1 day to 3 months old) were supplied by Froxfield Farms, Petersfield, Hampshire, UK. All procedures described in the present study were subject to Home Office approval, and were performed under the Animals (Scientific Procedures) Act 1986. The health and behaviour of the litters of rabbits in the chronic studies was checked on a day-to-day basis by the breeders' technician, and a named veterinary surgeon inspected the rabbits once a month as required by the Animals (Scientific Procedures) Act 1986.

\section{Study design}

Our primary aim was to assemble an efficient exposure chamber for rabbits that would provide a reliably stable chamber atmosphere. The most suitable equipment and components were first chosen and then tests were carried out under various conditions of airflow, humidity and different gas concentrations to determine the eventual parameters to be used during exposure of animals. Once these requirements had been satisfied and appropriate modifications to equipment made, we studied the effect of short-term exposures to $\mathrm{SO}_{2}$ in our chamber on the histamine responsiveness of adult rabbits. Exposure of neonatal rabbits was the final part of the study, in which we determined the effect of the daily exposure protocol upon the development of animals until 3 months of age.

\section{Chronic gas exposure protocol}

Chronic exposure of neonatally immunized rabbits, to air or the gases $\mathrm{NO}_{2}$ or $\mathrm{SO}_{2}$ from birth was performed at the animal suppliers' laboratory at Froxfield Farms by their trained personnel. On the day of birth, littermate rabbits were randomly ascribed to undergo exposure to either the gas under study or ambient air. Half the litter was removed from the nest box and transferred to the chamber for exposure to the appropriate atmosphere. When the first group was returned to their pen, their littermates were removed and taken to the chamber. This was repeated daily for 13 weeks, at which time the animals were transferred to our laboratory. Weights of animals were recorded 2 days after birth and, thereafter, every consecutive week.

\section{Chemicals}

Materials and chemicals were purchased from the following sources: nitrogen (BOC Ltd, London, UK); mixtures of $10 \% \mathrm{NO}_{2}$ in air and $10 \% \mathrm{SO}_{2}$ in air (BOC Ltd, Special Gases, Guildford, Surrey, UK); smoke pellets (PH Smoke Products Ltd, Wellingborough, Northamptonshire, UK); sterile aluminium hydroxide gel (Rehydragel; Reheis, Dublin, Eire); sterile pyrogen free $0.9 \%$ sodium chloride solution (saline; Baxter Health Care, Thetford, Norfolk, UK); Alternaria tenuis extract (40,000 PNU.ml- ${ }^{-1}$; Greer Laboratories Inc., Lenoir, North Carolina, USA); lyophilized allergen extract of Dermatophagoides pteronyssinus (Aquagen, ALK [503]; vial number 4, 100,000 SQ-U. $\mathrm{ml}^{-1}$; ALK Allergologisk Laboratorium A/S, Hørsholm, Denmark); histamine diphosphate (Sigma Chemical Co., Poole, Dorset, UK); diazepam injection BP $\left(5 \mathrm{mg} \cdot \mathrm{ml}^{-1}\right.$; Roche Products Ltd, Welwyn Garden City, Hertfordshire, UK); Hypnorm (a mixture of fentanyl citrate, $0.315 \mathrm{mg} \cdot \mathrm{ml}^{-1}$, and fluanisone, $10 \mathrm{mg} \cdot \mathrm{ml}^{-1}$; Janssen Pharmaceutical Ltd, Grove, Oxford, UK).

\section{The exposure chamber}

The $0.71 \mathrm{~m}^{3}$ exposure chamber (fig. 1), constructed from $2 \mathrm{~mm}$ (14 gauge) 304 grade stainless steel, is square in section, with pyramidal funnels formed top and bottom terminating in $40 \mathrm{~mm}$ pipes of $36 \mathrm{~mm}$ internal diameter (i.d.). Animal waste is washed, when necessary, from the chamber through the bottom of these pipes fitted with a sliding orifice plate. The pipe at the top of the chamber is attached to a series of 304 stainless steel pipes and the venturi tube, which together incorporate the gas delivery system and airflow monitoring and control devices. These tubes are bolted to each other by flanges. Air is drawn out of the chamber through a $36 \mathrm{~mm}$ i.d. exhaust pipe in the lower funnel, that has a series of 13 holes, $14.5 \mathrm{~mm}$ in diameter, drilled in the underside of the section within the chamber. The central section of the chamber is glazed on all sides over openings $795 \times 600$ $\mathrm{mm}$ to provide adequate internal lighting and excellent all round visibility. Plate glass $(5 \mathrm{~mm})$ windows form the side and back panels. These are attached to the steel framework of the chamber with double-sided adhesive foam tape $(0.8 \mathrm{~mm})$ and the edges are made airtight with silicone rubber sealant. The front opening forms a large 


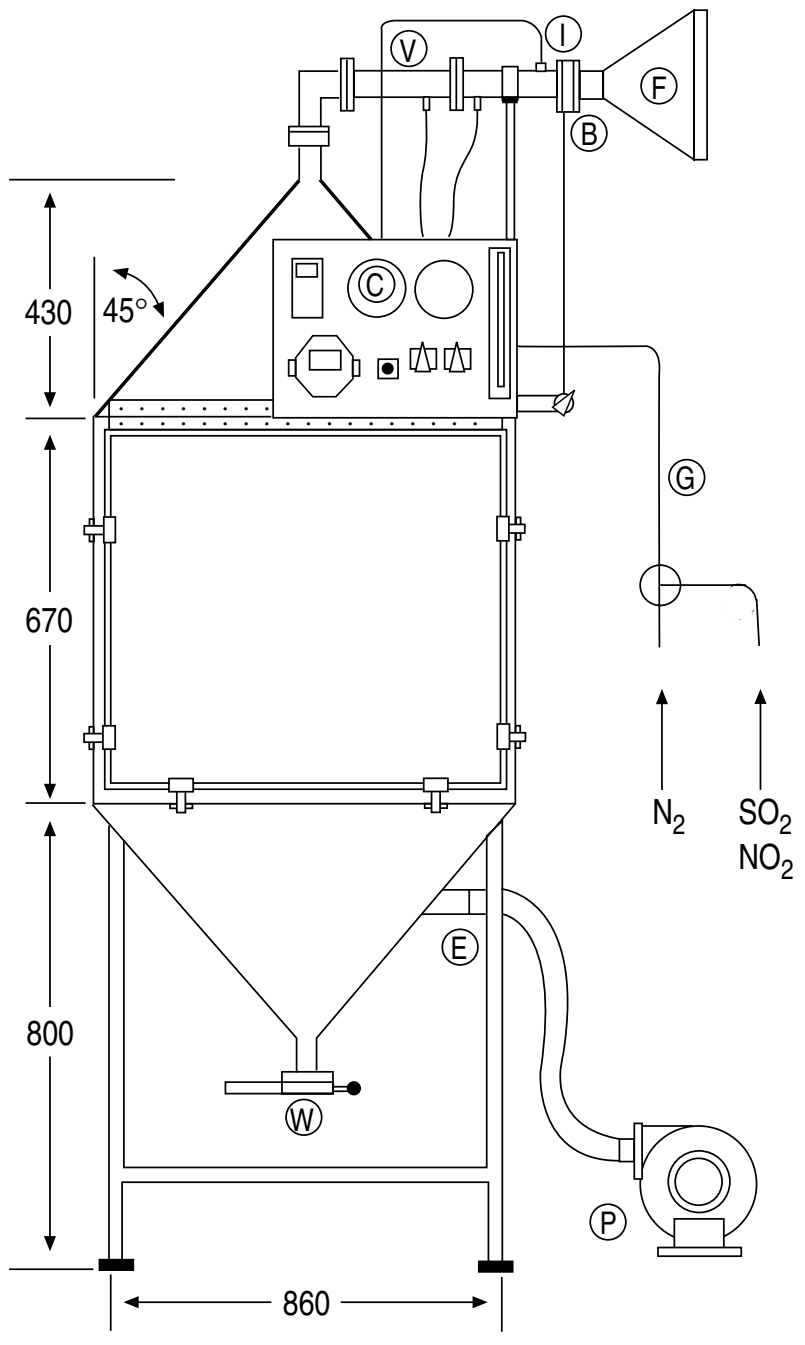

Fig. 1. - The exposure chamber. The circled letters indicate the position of the following parts of the control systems: F: inlet funnel and filter; B: butterfly damper valve; I: gas injection point; V: venturi tube; C: control panel; G: gas lines from gas cylinders; E: exhaust outlet; W: washing port valve; P: centrifugal exhaust fan. The measurements given refer to the dimensions of the chamber in $\mathrm{mm}$.

access door. This is constructed from $6 \mathrm{~mm}$ acrylic sheet, with a stainless steel angle frame attached to the front with double-sided adhesive foam tape. The door is fixed to the chamber body along its top edge by a piano hinge. Two adjustable quick-release toggle hook clamps located along each of the other edges provide a rapid fastening mechanism against the steel angle. A neoprene rubber gasket forms an airtight seal between the door and the chamber body. The chamber stands on four sturdy tubular steel legs and is easily movable. A control panel, on which are mounted all instruments and control devices, is mounted at a convenient height on the top of the chamber.

Animal cages may be placed at any desired position within the chamber by constructing suitable cage racks, which are fitted with ease into the square section of the chamber. However, in the present study, the rabbits were permitted complete freedom of movement within the chamber. A convenient support for the animals was provided by a modified galvanized steel wire $(2 \mathrm{~mm})$ mesh holding pen $(770 \times 770 \times 540 \mathrm{~mm})$ which rests on the slope of the lower funnel. These cages provide the normal housing for rabbits at the breeders' unit. Young rabbits, less than 3 weeks old, were placed in a nest box containing nest material for insulation and drilled with ventilation holes to allow free passage of gas around the animals. This box was placed in the centre of the cage during the period of exposure.

A number of holes drilled in the chamber walls provide access ports, which are required for instrumentation. Simple airtight ports for passing wires into the chamber are formed by passing the wire through a rubber grommet, that is held secure in a cable gland bolted to the chamber. A magnehelic gauge (Dwyer Instruments Inc., Michigan City, Indiana, USA; $0-50 \mathrm{~mm}$ range) connected to one port via silicon tubing measures the negative pressure within the chamber, which is maintained at $-30 \mathrm{mmH}_{2} \mathrm{O}$. This gauge provides an effective safety check on the various seals around the chamber. Temperature is monitored within the chamber by a remote sensor probe connected to an external electronic thermometer (RS Components Ltd, Corby, Northamptonshire, UK; model 612-849).

\section{Control of air supply and flow}

Airflow through the chamber is maintained by a 0.25 HP centrifugal fan with a radial blade impeller (B.O.B. Stevenson Ltd, Derby, Derbyshire, UK; model CA229), which has an output of $70 \mathrm{~m}^{3} \cdot \mathrm{h}^{-1}$ at $75 \mathrm{mmH}_{2} \mathrm{O}$ gauge pressure. The air supply to the chamber first passes through a coarse nylon mesh filter, to remove hair and large dust particles. The airflow is measured using a venturi type flow meter, and is controlled by means of a butterfly damper valve fitted between two flanges (fig. 2a). For animal exposure studies, the airflow was adjusted to $25 \mathrm{~m}^{3} \cdot \mathrm{h}^{-1}$, equivalent to 31 complete atmosphere changes per hour. Air is removed from the chamber to the exhaust fan through flexible polythene tubing, from where it is expelled to the external atmosphere.

\section{Monitoring of gas levels}

Gas concentrations within the chamber were monitored continuously by an electrochemical gas diffusion sensor (Enterra Instrumentation Technologies, Exton, Pennsylvania, USA; Sensor Stik, models 4583 and 4584) linked to a flatbed pen chart recorder (Rikadenki; model R-51), providing a trace of the gas concentration throughout the period of exposure. Additionally, a continuous digital read-out from the sensor was shown on an LCD display, mounted on the control panel next to the gas flow control valve.

\section{Control of gas levels}

Chamber concentrations of $\mathrm{NO}_{2}$ or $\mathrm{SO}_{2}$ were maintained at 4 or $5 \mathrm{ppm}$, respectively, by the manually-controlled dilution of cylinder gas in the stream of air from the inlet pipe. Gas is delivered from the pressurized cylinder to the gas flow control valve at 1 bar using a stainless steel 
a)

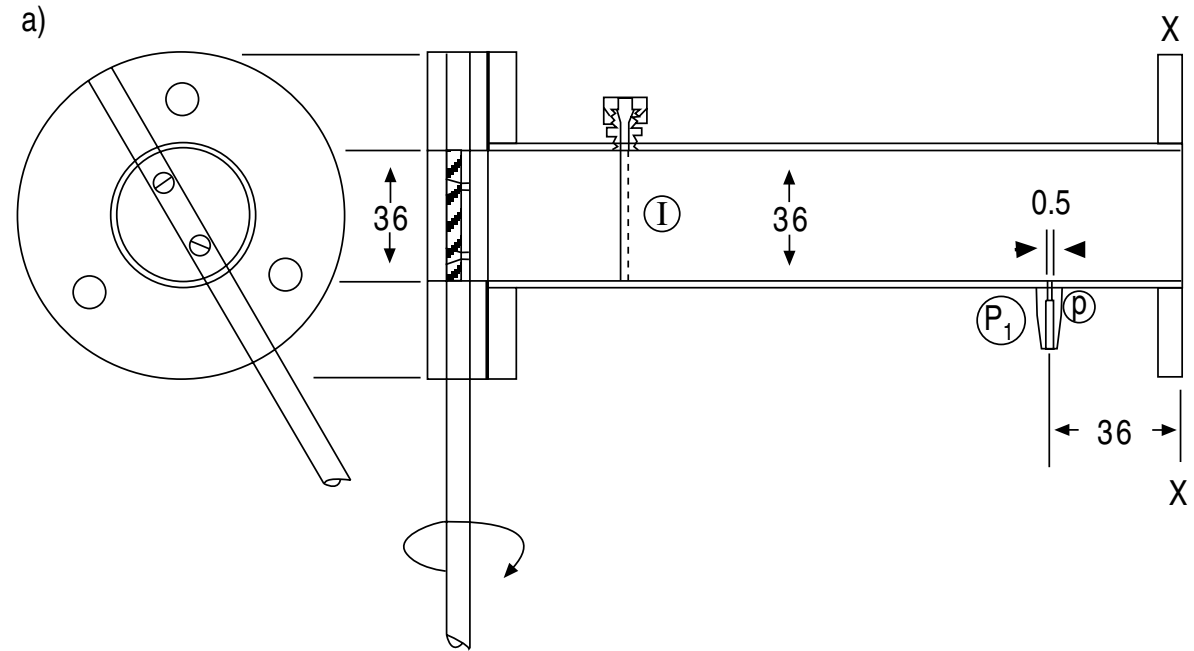

b)

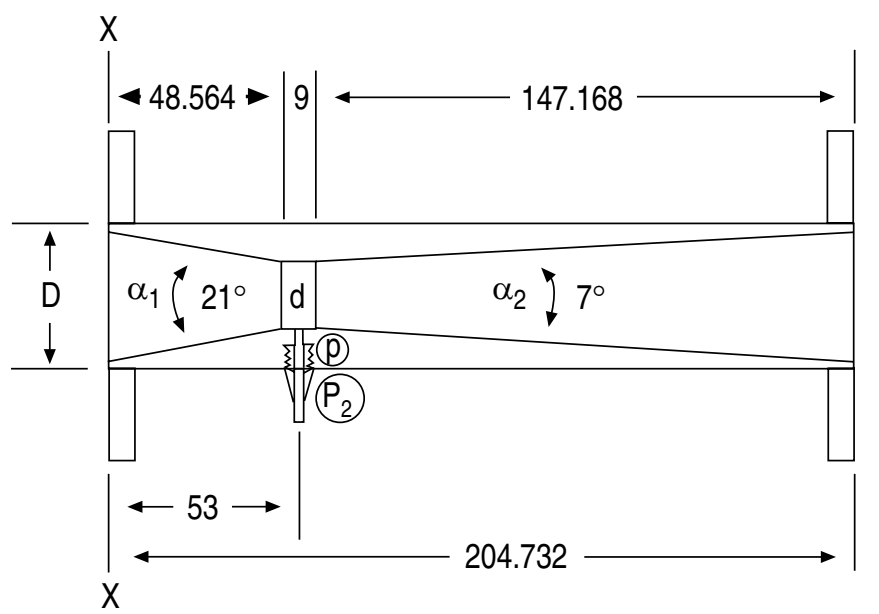

Fig. 2. - Details of: a) Butterfly damper, gas injector (I) and first pressure tap $\left(\mathrm{P}_{1}\right)$; b) Venturi tube. The second pressure tap ( $\left.\mathrm{P}_{2}\right)$ is placed in the centre of the throat of the venturi tube. The diameter of the throat (d) is $0.5 \times$ the diameter of the inlet pipe (D). Both pressure taps are 0.5 $\mathrm{mm}$ diameter and $5 \mathrm{~mm}$ in length (p). The direction of airflow is from left to right and the two tubes are bolted together at section $\mathrm{X}-\mathrm{X}$.. Measurements are given in $\mathrm{mm}$.

regulator (BOC Ltd, Special Gases; Spectrol regulator models 50S GE BS3 for $\mathrm{SO}_{2}$ and 50S GE BS14 for $\mathrm{NO}_{2}$ ) in $1 / 8 "(3.15 \mathrm{~mm}) 316 \mathrm{~L}$ grade stainless steel tubing (Fine Tubes Ltd, Plymouth, Devon, UK), and is passed first through a $7 \mu \mathrm{m}$ sintered stainless steel filter, then a rotameter (Supelchem UK Ltd, Saffron Walden, Essex, UK) which provides a visual marker of gas flow. A stainless steel needle valve (Brooks Instrument Division, Emerson Electric Co., Hatfield, Pennsylvania, USA; model 8744 ELF flow controller, needle size 1) gives fine control over gas flow. Gas is injected into the incoming air upstream of the venturi pipe through drilled $3.15 \mathrm{~mm}$ tubing (fig. 2a). The needle valve was used to adjust the gas flow to give the desired chamber concentration. At the end of the exposure time the gas supply was shut off and the system was flushed through with dry nitrogen to reduce corrosion due to build-up of sulphuric or nitric acids.

\section{The venturi flowmeter}

The velocity of fluid flow may be measured by the pressure difference across a constriction in the path of the fluid, such as an orifice plate (a perforated plate perpendicular to the flow) or venturi tube. Such devices may be permanently installed in a pipe. The venturi flowmeter was constructed of two components, the venturi tube and a magnehelic gauge, which is a mechanical replacement for a U-tube manometer. The venturi tube (fig. 2b) was machined from solid aluminium bar and then anodized.

The dimensions of the venturi tube used in the present study are given in figure $2 \mathrm{~b}$. For any venturi tube the inlet pipe diameter determines the overall dimensions. The two angles $\alpha_{1}$ and $\alpha_{2}$ should be equal to $21 \pm 2^{\circ}$ and between $5-15^{\circ}$, respectively. Details of flow meter theory may be found elsewhere $[11,20]$, but essentially the flow rate $\dot{Q}$ is derived from the following equation:

$$
\dot{Q}=\frac{C_{d} A_{1} A_{2} \sqrt{2 g \Delta h}}{\sqrt{A_{1}^{2}-A_{2}^{2}}}
$$

where $C_{d}$ is the coefficient of discharge of the venturi (approximately 0.98 for all venturis), $\mathrm{A}_{1}$ and $\mathrm{A}_{2}$ are the cross-sectional areas of the pipe and throat, respectively, 
and $\Delta \mathrm{h}$ is the head differential measured across the pressure taps $\mathrm{P}_{1}$ and $\mathrm{P}_{2}$ (fig. $2 \mathrm{~b}$; i.e. $\mathrm{P}_{1}-\mathrm{P}_{2}$ ). Thus, for a given flow rate, the required pressure difference must first be calculated.

\section{Chamber air and gas mixing}

Observations of the mixing of air during its passage through the chamber were carried out at a flow of 25 $\mathrm{m}^{3} \cdot \mathrm{h}^{-1}$, and were visualized with smoke generated by the combustion of smoke pellets placed in a modified inlet filter funnel. By the placement of light sources around the chamber and a black screen on one side, the passage of smoke through the chamber was observed from each side. The concentration of gas was measured at different levels and positions in the chamber by the gas sensor, to assess the extent of gas mixing.

Chronic exposure of animals to $\mathrm{SO}_{2}$ and $\mathrm{NO}_{2}$

Once animals were placed in the chamber and the door was sealed, the exhaust fan was switched on. When the desired airflow was obtained, the gas under study was introduced into the inlet pipe and allowed to reach the predetermined chamber concentration. The exposure time began when the chamber gas levels had equilibrated at $4 \mathrm{ppm}$ for $\mathrm{NO}_{2}$ and $5 \mathrm{ppm}$ for $\mathrm{SO}_{2}$. Two hours later, the gas supply was turned off and the gas in the chamber atmosphere was washed out, before the fan was switched off and the animals returned to their pens. Weights of the animals were recorded 2 days after birth and, thereafter, every consecutive week.

\section{Immunization protocol}

Rabbits were immunized from birth against Alternaria tenuis according to a previously published protocol [19], and against house dust mite (HDM) antigen using a modification of this method. Rabbits were injected intraperitoneally (i.p.) within $24 \mathrm{~h}$ of birth with $0.5 \mathrm{ml}$ of a mixture of an extract from either Alternaria tenuis or the house dust mite Dermataphagoides pteronyssinus, $\mathrm{Al}(\mathrm{OH})_{3}$ moist gel and saline, in the ratio of 2:1:1. The antigenadjuvant mixture $(0.5 \mathrm{ml})$ was repeatedly injected i.p. weekly for the first month, and then every two weeks for the following 2 months.

\section{Pulmonary function measurements}

Pulmonary function measurements were carried out on spontaneously breathing anaesthetized rabbits (2.2-3.1 $\mathrm{kg}$ ) using a minor modification of the method described previously [19]. Rabbits were first premedicated with diazepam $\left(2.5 \mathrm{mg} \cdot \mathrm{kg}^{-1}\right)$, and were subsequently administered Hypnorm $\left(0.4 \mathrm{ml} \cdot \mathrm{kg}^{-1}\right)$ to induce neuroleptalgesia. Animals were placed in the supine position and then intubated with a cuffed endotracheal tube. An oesophageal balloon, connected to a differential pressure transducer was inserted into the lower third of the oesophagus. The endotracheal tube was attached to a heated pneumotachograph connected to a second differential pressure transducer. Values for lung resistance $\left(\mathrm{R}_{\mathrm{L}}\right)$ and dynamic compliance (Cdyn) were calculated from measurements of flow and transpulmonary pressure (TPP) by means of an on-line respiratory analyser (PMS Version 4.0, Mumed Ltd, London, UK).

\section{Aerosolized histamine challenges}

Histamine challenges were performed on anaesthetized rabbits as described previously [19]. Aerosols of saline and histamine were generated by an ultrasonic nebulizer. After measurement of basal lung function parameters an aerosol of saline was administered directly into the lungs via the endotracheal tube for $2 \mathrm{~min}$. Lung function parameters were again measured to provide a control with which to compare the responses to histamine. Repeated measurements of lung function were then made following challenge with increasing concentrations of histamine ( $2 \mathrm{~min} ; 1.25-80 \mathrm{mg} \cdot \mathrm{ml}^{-1}$ aerosols). The provocation concentration of histamine that cumulatively produced a $50 \%$ increase in $\mathrm{RL}_{\mathrm{L}}\left(\mathrm{PC}_{50} \mathrm{RL}_{\mathrm{L}}\right)$ or a $35 \%$ decrease in Cdyn ( $\mathrm{PC}_{35} \mathrm{Cdyn}$ ) was determined for individual animals by linear interpolation, and used as indices of airway responsiveness

\section{Acute exposure to $\mathrm{SO}_{2}$}

To assess the acute effect of $\mathrm{SO}_{2}$ on airway responsiveness to histamine, measurements of pulmonary function were made before and after exposure for $2 \mathrm{hr}$ to $5 \mathrm{ppm}$ $\mathrm{SO}_{2}$. On day 1 , animals were anaesthetized, challenged with aerosolized histamine, and their lung function was measured. The following day the animals were placed in the chamber and exposed to $\mathrm{SO}_{2}$. Pulmonary function measurements after histamine were again measured on day 3 .

\section{Data analysis}

Values of gas concentrations and animal weights are expressed as the arithmetic mean. Basal lung function values for $\mathrm{R}_{\mathrm{L}}$, Cdyn, maximal TPP, respiration rate, tidal volume and minute volume are presented as arithmetic means. $\mathrm{PC}_{50} \mathrm{RL}$ and $\mathrm{PC}_{35} \mathrm{Cdyn}$ values are given as with the geometric means for each group of animals. Statistical analyses were performed using Student's paired or unpaired t-test or analysis of variance (ANOVA) followed by the Tukey-Kramer multiple comparison test, where appropriate. Results were considered significant if $\mathrm{p}<0.05$.

\section{Results}

\section{Distribution of gas in the chamber}

Preliminary experiments into the distribution and solubility of chamber gases were carried out on $\mathrm{SO}_{2}$ gas. 


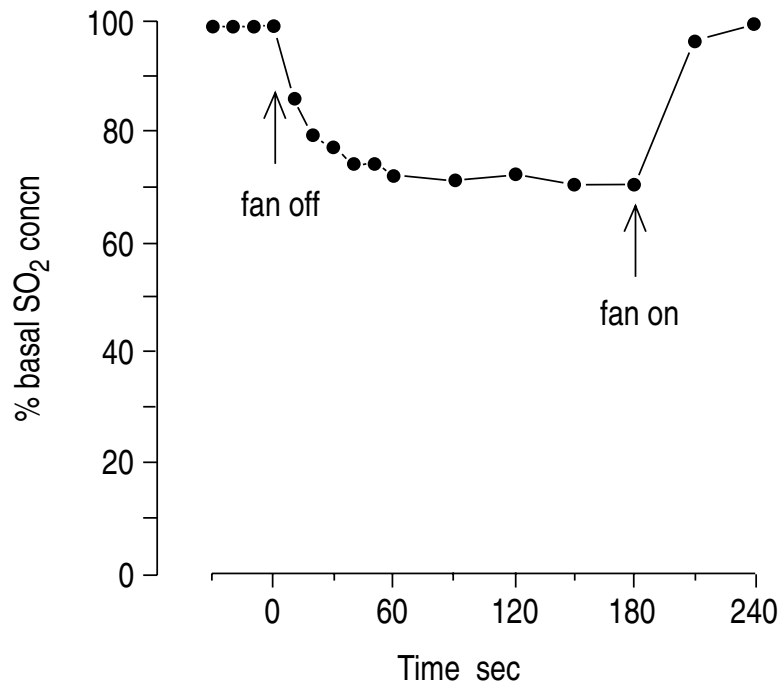

Fig. 3. - The effect of an air circulating fan on chamber $\mathrm{SO}_{2}$ concentration. This figure shows a representative experiment. $\mathrm{SO}_{2}$ was injected into the chamber through one of the ports, whilst the fan was circulating the chamber air, to approximately $8 \mathrm{ppm}$, and readings of the $\mathrm{SO}_{2}$ concentration were taken every 10-30 s. Once a steady baseline had been reached, the fan was switched off (at time $\mathrm{t}=0 \mathrm{~s}$ ). Three minutes later (a $\mathrm{t}=180 \mathrm{~s}$ ) the fan was switched on again.

Both $\mathrm{NO}_{2}$ and $\mathrm{SO}_{2}$ have densities greater than that of air. We were, therefore, concerned that under conditions of low airflow the gases would sink to the bottom of the chamber below the animals. Experiments were performed in a sealed chamber environment with a single gas sensor in the top funnel of the chamber and a small circulating fan placed at animal level. After injection of $\mathrm{SO}_{2}$ gas through one of the top chamber ports, the gas soon reached equilibrium. When the fan was switched off, the $\mathrm{SO}_{2}$ gas rapidly sank to the bottom of the chamber and the gas concentration fell by approximately $30 \%$, which was restored to its initial level once more when the fan was switched on and air was recirculated (fig. 3).

\section{Effect of humidity on chamber gas concentrations}

With a circulating fan within the sealed chamber the gas concentration was constant. However, when water $(100 \mathrm{ml})$ was injected into the chamber the gas concentration fell to zero (fig. 4a). Injection of further gas into the chamber restored the $\mathrm{SO}_{2}$ levels only briefly. When adult rabbits were placed in a sealed chamber with a fan circulating air, greater quantities of gas injected into the chamber were required to reach detectable levels (1-10 $\mathrm{ppm}$ ) than in an empty chamber. Under these conditions, the gas concentration rapidly fell after injection and this was repeated after further bolus injections of gas (fig. $4 b)$.

\section{Chamber airflow}

Smoke pellets were ignited in the stream of air flowing into the chamber to study the mixing of air within the chamber. Under the desired conditions of $25 \mathrm{~m}^{3} \cdot \mathrm{h}^{-1}$ airflow, air was found to emerge from the inlet tube and

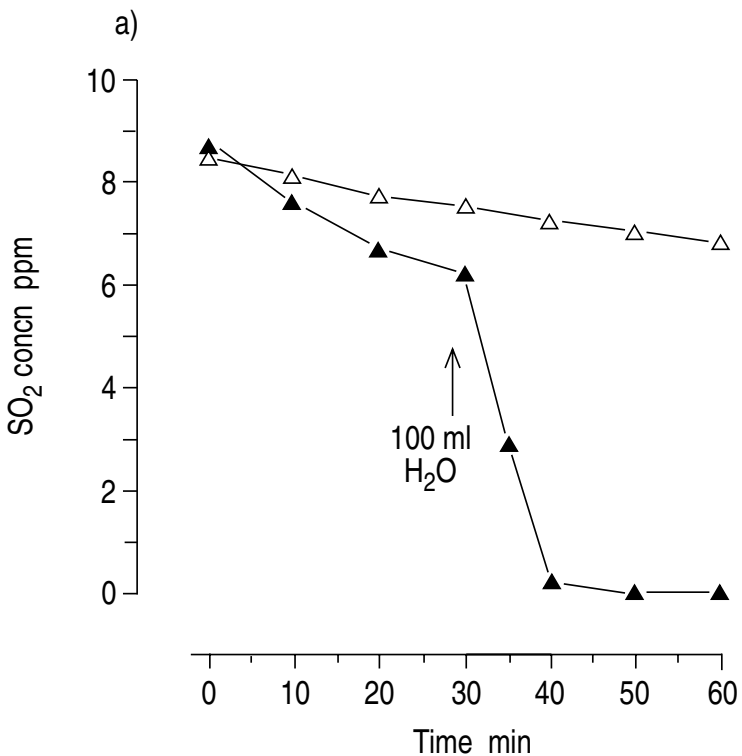

b)

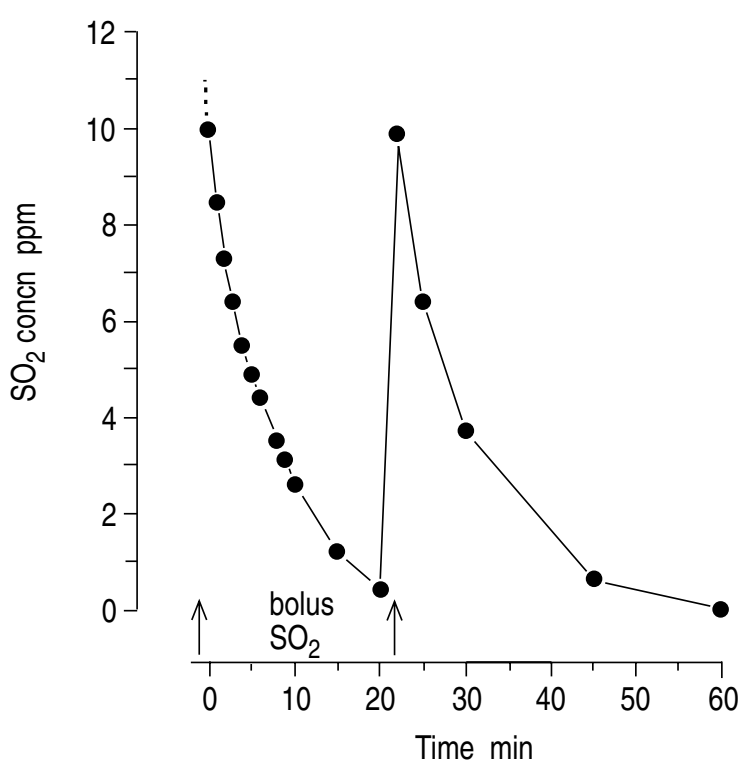

Fig. 4. - The effect of humidity on chamber $\mathrm{SO}_{2}$ concentration. This figure shows the results from two representative experiments conducted in a sealed chamber, with the circulating fan in place. a) Injection of $100 \mathrm{ml}$ of distilled water into the chamber results in an immediate fall in the measured $\mathrm{SO}_{2}$ concentration $(\boldsymbol{\Delta})$. The open symbols $(\Delta)$ show the $\mathrm{SO}_{2}$ concentration measured over the same period of time on a separate occasion. b) Shows the chamber $\mathrm{SO}_{2}$ concentration in the presence of four rabbits. Gas was injected in a bolus and the readings of gas concentration were made from $\mathrm{t}=0 \mathrm{~min}$ when $\mathrm{SO}_{2}$ was $\leq 10 \mathrm{ppm}$. The gas concentration rapidly fell close to zero. After fresh air was introduced into the chamber a second bolus injection of $\mathrm{SO}_{2}$ was made.

pass through the chamber to the lower funnel and exhaust tube in a column with very little mixing. Such a pattern of airflow would result in an uneven distribution of gas in the chamber, with a central region of high concentration and lower gas levels around the chamber edges. To combat this, we made a slight modification to the chamber. A square sheet of perspex $(610 \times 610 \times 6 \mathrm{~mm})$ was drilled with a geometric pattern of $15 \mathrm{~mm}$ diameter holes around an unperforated central circular area (total open area 
of 19\%). This was fixed in the upper funnel of the chamber, forming a baffle to the direct flow of air and, additionally, had the advantage of creating an effective mixing chamber above it. With this diffusion sheet in place, there was a gentle diffuse flow of air across the section of the chamber, and gas concentrations measured were constant throughout the chamber.

\section{Chamber temperature}

The internal chamber temperature corresponded to the laboratory temperature, between $16-18^{\circ} \mathrm{C}$. With the airflow of $25 \mathrm{~m}^{3} \cdot \mathrm{h}^{-1}$ there was no rise in the internal temperature of the chamber during the $2 \mathrm{~h}$ exposure of animals.

\section{Chamber gas concentration}

The concentration of gas within the chamber was reliably maintained at the set level for up to at least $8 \mathrm{~h}$. Once the required settings of the airflow and gas flow control valves had been determined, there was little daily adjustment required. Such adjustments were only necessary due to variations in the supplied cylinder gas concentrations. Figure 5 shows the pooled data from exposures performed on five consecutive days of a single litter of rabbits to $4 \mathrm{ppm} \mathrm{NO}_{2}$. There was a rapid (<10 min) equilibration of gas levels, which were constant over the next $2 \mathrm{~h}$ with less than $1 \%$ variation (for $\mathrm{NO}_{2}$ (mean \pm SEM) at $\mathrm{t}=\mathrm{x}$ min exposure; $\mathrm{t}=0,4.011 \pm 0.029 \mathrm{ppm} ; \mathrm{t}=60,4.052 \pm$ $0.022 \mathrm{ppm} ; \mathrm{t}=120,4.005 \pm 0.035 \mathrm{ppm} ; \mathrm{n}=5$ ). A similar degree of control was obtained for $\mathrm{SO}_{2}$ exposure concentrations $(\mathrm{t}=0,5.073 \pm 0.040 \mathrm{ppm} ; \mathrm{t}=60,5.044 \pm 0.029 \mathrm{ppm}$; $\mathrm{t}=120,5.062 \pm 0.019 \mathrm{ppm} ; \mathrm{n}=5)$. When the gas supply was turned off, only a short wash-out period was required before the animals could be removed.

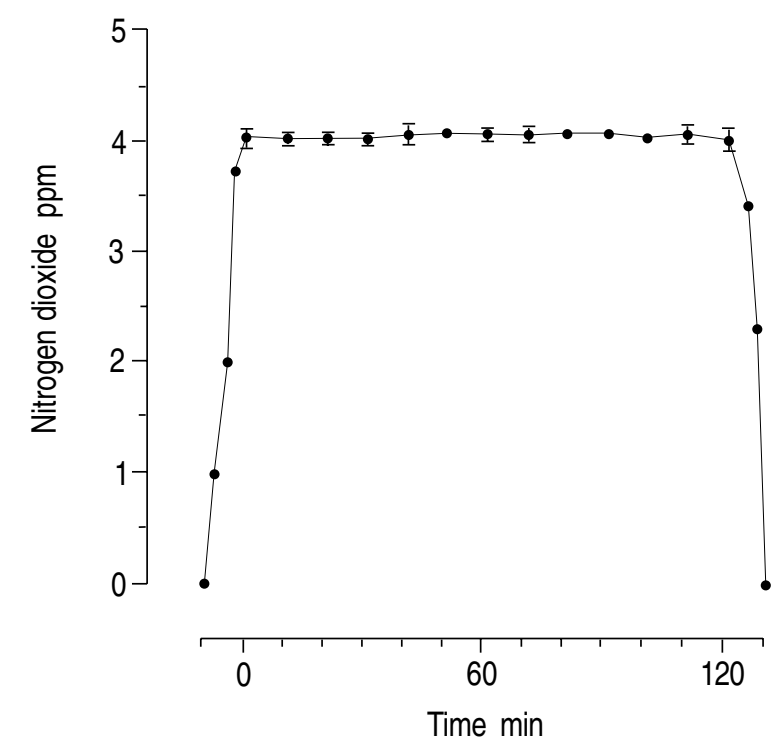

Fig. 5. - Chamber $\mathrm{NO}_{2}$ gas concentration from point of injection (at $\mathrm{t}=-10 \mathrm{~min}$ ) until wash-out (at $\mathrm{t}=120 \mathrm{~min}$ ), during routine exposure of rabbits at an airflow of $25 \mathrm{~m}^{3} \cdot \mathrm{h}^{-1}$ (equivalent to 31 complete air changes per hour). Results are the mean (SD) for $\mathrm{n}=5$ observations on successive days.
Effect of acute $\mathrm{SO}_{2}$ exposure on airways responsiveness in adult rabbits

Figure 6 shows the airways responsiveness to aerosolized histamine in naive adult rabbits measured on the days before and after a single $2 \mathrm{~h}$ exposure to $5 \mathrm{ppm} \mathrm{SO}_{2}$. Sulphur dioxide did not induce any change in responsiveness to histamine (mean \pm SEM values: $\mathrm{PC}_{50} \mathrm{RL}_{\mathrm{L}}$; pre-exposure, $11.5 \pm 1.69 \mathrm{mg} \cdot \mathrm{ml}^{-1}$, post exposure $14.18 \pm 1.44 \mathrm{mg} \cdot \mathrm{ml}^{-1}$ (p>0.05); $\mathrm{PC}_{35} \mathrm{Cdyn}$; pre-exposure $31.89 \pm 1.47 \mathrm{mg} \cdot \mathrm{ml}^{-1}$, post exposure $\left.30.28 \pm 1.34 \mathrm{mg} \cdot \mathrm{ml}^{-1}(\mathrm{p}>0.05)\right)$.

\section{Effect of exposure conditions on weight gain of animals}

Figure 7 shows the weights of immunized animals, exposed to either $\mathrm{NO}_{2}$ gas or ambient air, measured weekly over the first 3 months of life. There was no difference in weights between groups of immunized

a)

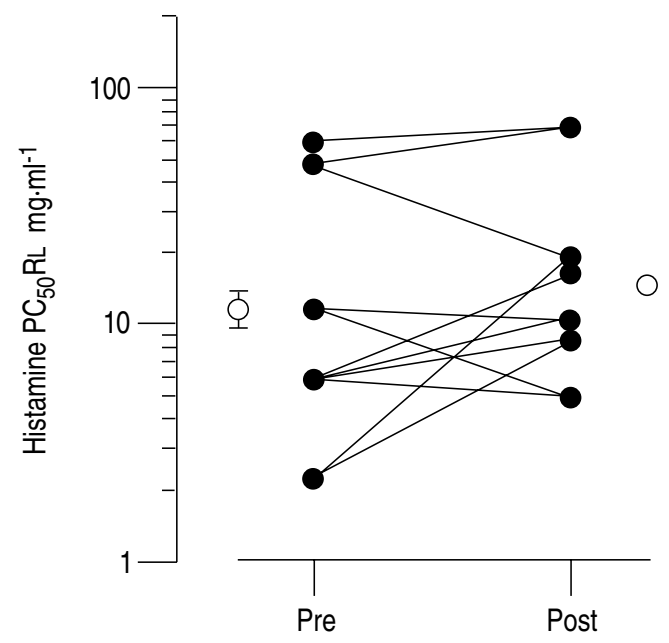

b)

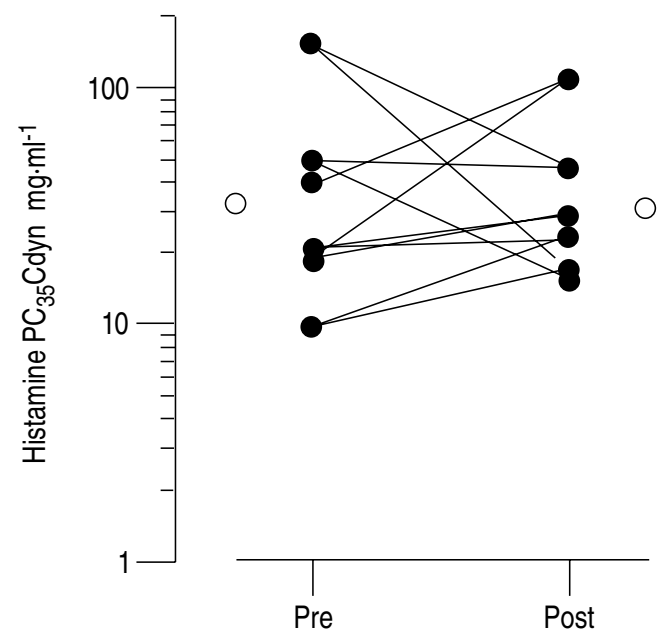

Fig. 6. - Effect of acute $\mathrm{SO}_{2}$ exposure (5 ppm, 2 h) on airways responsiveness to aerosolized histamine. a) histamine $\mathrm{PC}_{50} \mathrm{RL}$ is the concentration of histamine required to cause a $50 \%$ increase in total airways resistance $(\mathrm{RL})$; b) histamine $\mathrm{PC}_{35} \mathrm{Cdyn}$ is the concentration of histamine required to cause a $35 \%$ decrease in dynamic compliance (Cdyn). - : $\mathrm{PC}_{50} \mathrm{RL}$ and $\mathrm{PC}_{35} \mathrm{Cdyn}$ values from individual rabbits $24 \mathrm{~h}$ before (Pre) and $24 \mathrm{~h}$ after (post) gas exposure; $\bigcirc$ : geometric mean \pm SEM values $(n=6$ rabbits per group). Note logarithmic scale for histamine concentration. 


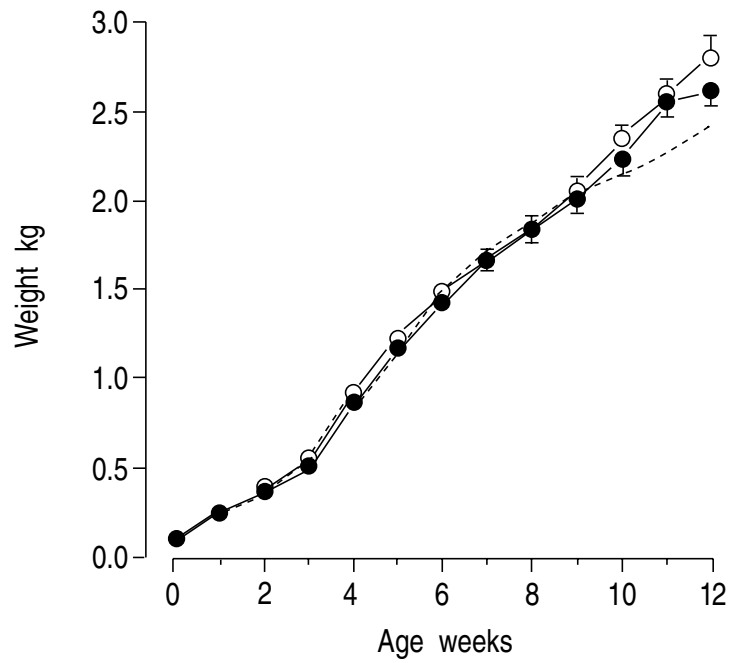

Fig. 7. - Weight gain of rabbits exposed to either ambient air ( $\supset$, $\mathrm{n}=11-18)$ or $4 \mathrm{ppm} \mathrm{NO}$ for $2 \mathrm{~h}$ daily $(\bullet, \mathrm{n}=9-18)$. Values are mean \pm SEM. The dotted line represents typical values for naive New Zealand White rabbits.

animals at any of the time-points ( $>00.05)$. Figure 7 also shows the growth curve from birth that is typical of naive New Zealand White rabbits (data supplied by Froxfield Farms). The weights of the immunized animals did not differ from that expected for naive animals in the breeders' colony.

Effect of long-term exposure to $\mathrm{SO}_{2}$ and $\mathrm{NO}_{2}$ on basal pulmonary function measurements

Basal pulmonary function values obtained from 3 month old spontaneously breathing anaesthetized naive rabbits,
Alternaria-immunized rabbits exposed to either air or $\mathrm{SO}_{2}$, HDM-immunized and saline-injected littermate control rabbits and HDM-immunized rabbits exposed to either air or $\mathrm{NO}_{2}$ are presented in table 1. There was no difference in values of RL, Cdyn, maximal transpulmonary pressure (TPP) or respiration rate between any of the groups of rabbits $(\mathrm{p}>0.05)$, and no values obtained for littermate control animals differed significantly from their corresponding test groups $(\mathrm{p}>0.05)$. However, there were significant differences in tidal volumes between HDM-immunized rabbits exposed to $\mathrm{NO}_{2}$ and both saline-injected rabbits $(\mathrm{p}<0.05)$, and naive animals $(\mathrm{p}<0.001)$. The values obtained for minute volume for both air exposed HDM-immunized rabbits and salineinjected rabbits differed significantly from those obtained for naive rabbits $(\mathrm{p}<0.05)$.

\section{Discussion}

We have developed an exposure chamber suitable for the study of the acute and chronic effects of pollutant gases such as $\mathrm{SO}_{2}$ and $\mathrm{NO}_{2}$, on respiratory parameters in animals. The chamber has been constructed at relatively modest expense, and the atmosphere control systems are simple to operate and reliable in use. Conditions of airflow and chamber gas levels are maintained at constant values over several hours. The small variation of gas levels over time $(<1 \%)$ was well within our initial goal of a $5 \%$ fluctuation around the desired concentration (i.e. $\left.\mathrm{SO}_{2} 5.0 \pm 0.25 \mathrm{ppm} ; \mathrm{NO}_{2} 4.0 \pm 0.20 \mathrm{ppm}\right)$. On a long-term basis, little daily adjustment of the chamber controls was found to be necessary.

Table 1. - Measurements of basal pulmonary function parameters made in spontaneously breathing anaesthetized 3 month old rabbits

\begin{tabular}{|c|c|c|c|c|c|c|c|}
\hline Group & $\mathrm{n}$ & $\begin{array}{c}\mathrm{RL} \\
\mathrm{cmH}_{2} \mathrm{O} \cdot l^{-1} \cdot \mathrm{s}^{-1}\end{array}$ & $\begin{array}{c}\text { Cdyn } \\
\mathrm{ml} \cdot \mathrm{cmH}_{2} \mathrm{O}^{-1}\end{array}$ & $\begin{array}{c}\text { Maximum TPP } \\
\mathrm{cmH}_{2} \mathrm{O}\end{array}$ & $\begin{array}{l}\text { Tidal volume } \\
\mathrm{ml}\end{array}$ & $\begin{array}{l}\text { Respiration rate } \\
\text { breaths } \cdot \mathrm{min}^{-1}\end{array}$ & $\begin{array}{l}\text { Minute volume } \\
\qquad \cdot \mathrm{min} \mathrm{m}^{-1}\end{array}$ \\
\hline a) Naive & 16 & $\begin{array}{c}31.28 \\
(15.21-48.94)\end{array}$ & $\begin{array}{c}4.23 \\
(2.63-7.35)\end{array}$ & $\begin{array}{c}3.60 \\
(2.40-5.47)\end{array}$ & $\begin{array}{c}12.77 \\
(8.7-17.78)\end{array}$ & $\begin{array}{c}37 \\
(20-80)\end{array}$ & $\begin{array}{c}0.42 \\
(0.24-0.72)\end{array}$ \\
\hline \multicolumn{8}{|c|}{ b) Alternaria } \\
\hline Air & 3 & $\begin{array}{c}33.05 \\
(24.97-43.68)\end{array}$ & $\begin{array}{c}4.48 \\
(4.08-5.21)\end{array}$ & $\begin{array}{c}3.95 \\
(3.62-4.51)\end{array}$ & $\begin{array}{c}15.95 \\
(13.28-20.76)\end{array}$ & $\begin{array}{c}35 \\
(15-54)\end{array}$ & $\begin{array}{c}0.50 \\
(0.31-0.72)\end{array}$ \\
\hline $\mathrm{SO}_{2}$ & 4 & $\begin{array}{c}34.04 \\
(20.34-51.35)\end{array}$ & $\begin{array}{c}4.12 \\
(3.63-4.64)\end{array}$ & $\begin{array}{c}4.15 \\
(3.58-5.19)\end{array}$ & $\begin{array}{c}14.92 \\
(10.47-17.88)\end{array}$ & $\begin{array}{c}44 \\
(21-103)\end{array}$ & $\begin{array}{c}0.57 \\
(0.37-1.08)\end{array}$ \\
\hline \multicolumn{8}{|l|}{ c) $\mathrm{HDM}$} \\
\hline Air & 12 & $\begin{array}{c}29.50 \\
(17.59-37.04)\end{array}$ & $\begin{array}{c}4.28 \\
(2.10-6.01)\end{array}$ & $\begin{array}{c}4.19 \\
(2.91-6.61)\end{array}$ & $\begin{array}{c}16.98 \\
(10.30-29.85)\end{array}$ & $\begin{array}{c}47 \\
(15-122)\end{array}$ & $\begin{array}{c}0.69^{*} \\
(0.37-1.28)\end{array}$ \\
\hline $\mathrm{NO}_{2}$ & 15 & $\begin{array}{c}32.79 \\
(23.18-52.42)\end{array}$ & $\begin{array}{c}4.94 \\
(3.56-7.89)\end{array}$ & $\begin{array}{c}4.57 \\
(2.59-7.77)\end{array}$ & $\begin{array}{c}20.08 * * \\
(11.34-34.44)\end{array}$ & $\begin{array}{c}34 \\
(14-94)\end{array}$ & $\begin{array}{c}0.59 \\
(0.37-1.06)\end{array}$ \\
\hline d) Saline & 7 & $\begin{array}{c}28.98 \\
(21.56-32.70)\end{array}$ & $\begin{array}{c}3.82 \\
(2.71-4.96)\end{array}$ & $\begin{array}{c}4.01 \\
(3.15-4.59)\end{array}$ & $\begin{array}{c}12.93^{\dagger} \\
(9.27-18.01)\end{array}$ & $\begin{array}{c}61 \\
(19-102)\end{array}$ & $\begin{array}{c}0.72 * \\
(0.34-0.96)\end{array}$ \\
\hline HDM & 6 & $\begin{array}{c}32.10 \\
(20.35-39.27)\end{array}$ & $\begin{array}{c}4.78 \\
(3.43-6.44)\end{array}$ & $\begin{array}{c}4.59 \\
(3.20-5.79)\end{array}$ & $\begin{array}{c}19.03 \\
(17.85-20.79)\end{array}$ & $\begin{array}{c}22 \\
(14-27)\end{array}$ & $\begin{array}{c}0.41 \\
(0.30-0.52)\end{array}$ \\
\hline
\end{tabular}

Measurements were obtained from: a) naive rabbits; b) littermate Alternaria-immunized rabbits exposed to either ambient air or $\mathrm{SO}_{2}\left(5 \mathrm{ppm}, 2 \mathrm{~h} \cdot \mathrm{day}^{-1}\right)$ from birth; c) littermate HDM-immunized rabbits exposed to either ambient air or $\mathrm{NO}_{2}\left(4 \mathrm{ppm}, 2 \mathrm{~h} \cdot \mathrm{day}^{-1}\right)$ from birth; d) rabbits immunized against HDM and their saline-injected littermate controls. Data are presented as arithmetic mean, with range in parenthesis. ${ }^{\dagger}: \mathrm{p}<0.05$, compared with $\mathrm{NO}_{2}$ exposed animals; $*$ : $\mathrm{p}<0.05$, compared with naive group; **: $\mathrm{p}<0.001$, compared with naive group. HDM: house dust mite; RL: lung resistance; Cdyn: dynamic compliance; TPP: transpulmonary pressure. 
We decided to use an airflow of $25 \mathrm{~m}^{3} \cdot \mathrm{h}^{-1}$, which gave 31 complete atmosphere changes per hour. This flow rate was chosen because it gave a reasonable number of air changes; thereby, keeping humidity and carbon dioxide build-up down. Gas concentrations were reliably constant and readily obtained by dilution of cylinder gas, and it gave an economical use of cylinder gases.

The chambers used were constructed of stainless steel and follow the basic design, described previously [11, $21,22]$, of a rectangular cuboidal centre section with pyramidal funnels top and bottom. It might be imagined that with this design there is a good mixing of the incoming air in the upper tapered section. However, smoke tests revealed that this is far from the case. To combat the problem of nonhomogenous atmospheres, circulating fans have been used to mix the air within exposure chambers $[23,24]$. We took another approach, making one modification to the design by the addition of the diffuser sheet after we had observed the unequal passage of smoke through the chamber. The diffuser sheet produced a laminar airflow visualized by smoke, and homogenous chamber atmosphere when gas levels were measured. Under identical conditions of airflow and gas delivery, the gas concentration at different positions and levels of the chamber were measured. The gas concentration did not differ at any of the monitoring points. These experiments were later repeated with animals present in the chamber and the distribution of gas was again found to be uniform (results not shown). The diffuser sheet, thus, provides a convenient mounting point for the gas sensor, since the gas concentration at the top of the chamber is identical with that at animal level.

Others have reported a similar modification to this basic design on encountering the same problem of concentrated airflow [22]. The solution employed by Holmberg et al. [22] was to add an assembly of a dispersing cone mounted on the upper of two parallel laminarizing screens of perforated aluminium sheet installed in the upper tapered section of the chamber. The free openings on the diffuser sheet are much larger than the small holes on the laminarizing screens described previously [22], and the total open area of $19 \%$ is greater than that of $10 \%$ [22]. However, the simple diffuser that we have used works efficiently and is inexpensive to manufacture, and it is likely that any similar design will have the desired effect.

It has been reported that there is equal distribution of gas concentration within a cuboidal chamber [21, 25]. The supposed problem of nonhomogenous atmospheres or low gas concentrations has been suggested to be the result of poor sampling techniques [26]. It may also be argued that once the chamber atmosphere has reached equilibrium with the incoming gas levels, there is a homogenous environment [26]. However, whilst this may hold true for chronic exposure studies with continuous exposure for a number of weeks, it does present a problem when short exposure times, such as those employed in the present study, are used. In such cases, the time for the chamber atmosphere to reach equilibrium may approach the total exposure time and there is, therefore, a need to keep equilibration times to a minimum.
Measurement and control of atmospheric gas concentrations of $\mathrm{SO}_{2}, \mathrm{NO}_{2}$ and other pollutants may be made in several different ways. In exposure chamber studies, use has been made of a metered gas delivery system [27], analytical chemical methods [11, 28-30], gas adsorbent tubes [31,32] and gas analysers [33-35], or other gas sensors providing a continuous read-out. Our choice of gas sensor was influenced by three factors, namely reliability, sensitivity and cost. The probes chosen have a sensitivity range similar to the range of concentrations which we intended to study. The sensors have proved very reliable and are maintenance-free, excepting the periodic replacement of the electrochemical sensor unit as recommended by the manufacturer. The main advantages of the sensors are their low cost, compactness and robustness, when compared to more sophisticated gas analysers, and the flexibility they offer since they are available for the monitoring of a number of hazardous gases at a range of concentrations.

Airflow was found to be best controlled by a simple butterfly damper valve inserted into the inlet pipe. This has advantages over a variable rheostat on the fan. There is an almost immediate change to the measured airflow, thus simplifying operation, and the fan motor is run at the correct voltage. Centrifugal fans are very efficient and reliable, and are widely available in a range of sizes. However, use may be made of other air pumps. In our own laboratory, air is drawn through a much smaller chamber than that presently described, by means of a modified vacuum cleaner motor and fan.

Control of gas dilution into the incoming air stream was achieved with a stainless steel fine needle valve, designed to work efficiently at low pressures and extremely low flows. Less expensive brass valves and other components soon became inefficient and unreliable on repeated exposure to the corrosive gases used in this study. Thus, all other pipes and tubing used were of stainless steel. A purging system in the gas injection line, through which dry nitrogen is flushed after each use, prevents corrosion due to dissolution of the $\mathrm{SO}_{2}$ and $\mathrm{NO}_{2}$ in condensation.

The second part of our study was to investigate the effects of long-term exposure to $\mathrm{SO}_{2}$ and $\mathrm{NO}_{2}$ on neonatally immunized rabbits. Before conducting chronic exposure studies, we determined the effect of a single exposure to $\mathrm{SO}_{2}$ on histamine responsiveness in naive adult rabbits. Exposure to $5 \mathrm{ppm} \mathrm{SO}_{2}$ for $2 \mathrm{~h}$ did not result in an alteration of airways responsiveness to inhaled histamine the following day. One of our major concerns was the possible reaction of the does to the daily removal of their offspring at such an early stage for several hours at a time. However, all of the does tolerated the brief disappearance of their litters very well. No effect of the exposure protocol on the mortality, health or behaviour of the young immunized rabbits was noted, and their growth was unaffected by exposure to $\mathrm{NO}_{2}$ from birth. We also compared basal pulmonary function measurements of animals at 3 months of age. The measurements made for RL, Cdyn, respiration rates, tidal volumes and minute volumes compare favourably with values reported previously for the rabbit $[19,36]$. There were no 
differences between basal values obtained for RL, Cdyn, maximum TPP or respiration rate between naive rabbits, groups of immunized rabbits exposed to air or $\mathrm{SO}_{2}$, air or $\mathrm{NO}_{2}$, or HDM-immunized rabbits and their salineinjected controls. We are unable to explain the differences in tidal and minute volumes between some of the groups, but the ranges of values for each parameter were similar in all of the groups. There were no differences in any of the values obtained for each parameter between groups of littermate rabbits treated differently. The observed differences may, therefore, be an artefact due to differences between litters, rather than a result of the treatment.

Increased air pollution has been implicated in the pathogenesis of asthma and other allergic disorders [5-9]. Studies on the immunization of adult animals have demonstrated increased sensitization following exposure to pollutants $[6,23,24,31]$. It is, however, evident that it is the primary exposure to an allergen that occurs during early childhood that determines subsequent sensitivity to that allergen [37]. This suggests that studies on young animals would be of more relevance. Neonatal immunization of rabbits results in the preferential production of $\mathrm{IgE}$ antibodies [12], and hyperresponsiveness to histamine [29]. We therefore developed a system for the long-term exposure of rabbits to pollutants from birth. In the future, we will determine the effect of pollutant gases, such as $\mathrm{SO}_{2}$ and $\mathrm{NO}_{2}$, on the development of airways hyperresponsiveness in neonatally immunized rabbits, to investigate the putative role of air pollutants in the aetiology of allergic asthma.

Acknowledgements: The authors thank the Wellcome Trust for support (Project Grant number 034840/Z/91/Z); R. Rylander (Department of Environmental Hygiene, University of Göthenburg, Sweden) for donating the chamber; J. Congram (Department of Pharmacology, King's College, London, UK) for fabricating the additional components; T. Richards, J. Gilbert and C. Jackson (Froxfield Farms, Hampshire, UK) for invaluable technical support.

\section{References}

1. Burney P. Asthma deaths in England and Wales 1931-1985: evidence for a true increase in asthma mortality. $J$ Epidemiol Commun Health 1988; 42: 316-320.

2. Burney PGJ. Strategy for asthma. Br Med J 1991; 303: 571-573.

3 Woolcock AJ. Worldwide trends in asthma morbidity and mortality. Explanation of trends. Bull Int Union Tuberc Lung Dis 1991; 66: 85-89.

4. Landau LI. Development of respiratory symptoms and bronchial hyperresponsiveness in infancy. Pediatr Allergy Immunol 1992; 3: 61-65.

5. Holt PG. Environmental pollutants as co-factors in IgE production. Curr Opin Immunol 1989; 1: 643-646.

6. Riedel F. Influence of adjuvant factors on development of allergy. Pediatr Allergy Immunol 1991; 2: 15.

7. Pierson WE, Koenig JQ. Respiratory effects of air pollution on allergic disease. J Allergy Clin Immunol 1992; 90: 557-566.

8. Bråbäck L, Kälvesten L. Urban living as a risk factor for atopic sensitzation in Swedish schoolchildren. Pediatr Allergy Immunol 1991; 2: 14-19.

9. Wardlaw AJ. The role of air pollution in asthma. Clin Exp Allergy 1993; 23: 81-96.

10. Schreck RM, Chan TL, Soderholm SC. Design, operation and characterization of large volume exposure chambers. In: Leong BKJ, ed. Inhalation Toxicology and Technology. Collingwood, Ann Arbor Science, 1981; pp. 2952.

11. Hinners RG, Burkart JK, Pune CL. Animal inhalation exposure chambers. Arch Environ Health 1968; 16: 194-206.

12. Pinkard RN, Halonen M, Meng AL. Preferential expression of anti-bovine serum albumin IgE homocytotropic antibody synthesis and anaphylactic sensitivity in the neonatal rabbit. J Allergy Clin Immumol 1972; 49: 301-310.

13. Shampain MP, Behrens BL, Larsen GL, Henson PM. An animal model of late pulmonary responses to Alternaria challenge. Am Rev Respir Rev 1982; 126: 493-498.

14. Murphy KR, Wilson MC, Irvin CG, et al. The requirement for polymorphonuclear leukocytes in the late asthmatic response and heightened airway reactivity in an animal model. Am Rev Respir Dis 1986; 134: 62-68.

15. Coyle AJ, Page CP, Atkinson L, Sjoerdsma K, Touvay $\mathrm{C}$, Metzger WJ. Modification of late onset airway obstruction and bronchial hyperresponsiveness in an allergic model by the selective platelet activating factor antagonist BN 52021. J Allergy Clin Immunol 1989; 84: 960-967.

16. Larsen GL, Wilson MC, Clark ARF, Behrens BL. The inflammatory reaction in the airway in an animal model of the late asthmatic response. Fed Proc 1987; 46: 105-112.

17. Marsh WR, Irvin CG, Murphey KR, Behrens BL, Larsen GL. Increases in airway reactivity to histamine and inflammatory cells in bronchoalveolar lavage after the late asthmatic response in an animal model. Am Rev Respir Rev 1985; 131: 875-879.

18. Herd CM, Donigi-Gale D, Shoupe S, Burroughs M, Yeadon M, Page CP. Effect of a 5-lipoxygenase inhibitor and leukotriene antagonist (PF 5901) on antigeninduced airway responses in neonatally immunized rabbits. Br J Pharmacol 1994; 112: 292-298.

19. Minshall EM, Riccio MM, Herd CM, et al. A novel model for investigating persistent airway hyperresponsiveness. J Pharmacol Toxicol Methods 1993; 30: $177-188$.

20. Daugherty RL, Franzini JB, Finnemore EJ. In: Fluid Mechanics with Engineering Applications. New York, McGraw-Hill. 8th edn. 1985; pp. 418-428.

21. Hinners RG, Burkart JK, Contner GL. Animal exposure chambers in air pollution studies. Arch Environ Health 1966; 13: 609-615.

22. Holmberg RW, Moneyhun JH, Dalbey WE. An exposure system for toxicological studies of concentrated oil aerosols. In: Leong BKJ, ed. Inhalation Toxicology and Technology. Collingwood, Ann Arbor Science, 1981; pp. 53-64.

23. Miyamoto T, Matsumura Y, Kodama T, Saito T. Effect of sulphur dioxide upon respiratory sensitisation in animals. Jap J Allergy 1968; 17: 179-182.

24. Riedel F, Kräme M, Scheibenbogen C, Rieger CHL. Effects of $\mathrm{SO}_{2}$ exposure on allergic sensitisation in the guinea-pig. J Allergy Clin Immunol 1988; 82: 527-534.

25. Silver SD. Constant flow gassing chambers: principles influencing design and operation. J Lab Clin Med 1946; 31: 1153-1161. 
26. MacFarland HN. A problem and a non-problem in chamber inhalation studies. In: Leong BKJ, ed. Inhalation Toxicology and Technology. Collingwood, Ann Arbor Science, 1981; pp. 11-18.

27. Sherwin RP, Yuen TGH. Silicone fluid for the metering and monitoring of nitrogen dioxide. Arch Environ Health 1972; 24: 331-336.

28. Thomas MD, Abersold JN. Automatic apparatus for the determination of small concentrations of sulfur dioxide in air. II. Ind Eng Chem 1929; 1: 14-15.

29. Saltzman BE. Colorimetric microdetermination of nitrogen dioxide in the atmosphere. Anal Chem 1954; 26: 1949-1955.

30. Naumann RV, West PW, Tron F, Gaeke GC. Spectrophotometric studies of the Schiff reaction as applied to quantitative determination of sulphur dioxide. Anal Chem 1960; 32: 1307-1311.

31. Riedel F, Nüßlein T, Rüschoff J, Rieger CHL. Tobacco smoke enhances allergic bronchial sensitization in the guinea-pig. Pediatr Allergy Immunol 1990; 1: 2633.

32. Yeadon M, Wilkinson D, Darley-Usmar V, O'Leary VJ, Payne AN. Mechanisms contributing to ozone-induced bronchial hyperreactivity in guinea-pigs. Pulmon Pharmacol 1992; 5: 39-50.

33. Kobayashi T, Morita I, Murota S-I. Effects of nitrogen dioxide exposure on prostacyclin synthesis in lung and thromboxane $\mathrm{A}_{2}$ synthesis in platelets in rats. Prostaglandins 1983; 26: 303-310.

34. Schlesinger RB, Driscoll KE, Vollmuth TA. Effect of repeated exposures to nitrogen dioxide and sulfuric acid mist alone or in combination on mucociliary clearance from the lungs of rabbits. Environ Res 1987; 44: 294-301.

35. Rose RM, Fuglestad JM, Skornik WA, et al. The pathophysiology of enhanced susceptibility to murine cytomegalovirus respiratory infection during short-term exposure to $5 \mathrm{ppm}$ nitrogen dioxide. Am Rev Respir Dis 1988; 137: 912-917.

36. Kozma C, Macklin W, Cummins LM, Mauer R. Anatomy, physiology and biochemistry of the rabbit. In: Weisbroth SH, Flatt RE, Kraus AL, eds. The Biology of the Laboratory Rabbit. Orlando, Academic Press Inc., 1974; pp. 49-72.

37. Holt PG, McMenamin C, Nelson D. Primary sensitisation to inhalant allergens during infancy. Pediatr Allergy Immunol 1990; 1: 3-13. 